\title{
Study on Relativity between China's Nominal GDP and the Shanghai Securities Composite Index
}

\author{
Dahong Guan \\ Jinan University, Guangzhou, China \\ Email: dahongguan2015@gmail.com
}

How to cite this paper: Guan, D.H. (2018) Study on Relativity between China's Nominal GDP and the Shanghai Securities Composite Index. Journal of Service Science and Management, 11, 527-542.

https://doi.org/10.4236/jssm.2018.115036

Received: September 29, 2018

Accepted: October 26, 2018

Published: October 29, 2018

Copyright $\odot 2018$ by author and Scientific Research Publishing Inc. This work is licensed under the Creative Commons Attribution International License (CC BY 4.0).

http://creativecommons.org/licenses/by/4.0/

\section{(c) (i) Open Access}

\begin{abstract}
By implementing X-11 process to eliminate the seasonal effect from the data of nominal GDP and Shanghai Securities Composite Index from 1996 to 2015, conducting co-integration test and Granger causality test on these processed data, and examining the leading characteristics of the securities index with the Lag regression model, the present thesis finally conducts a detailed analysis of the research results and puts forward some policy recommendations. The study suggests that there is a stable positive-correlating long-term relationship between Shanghai securities composite index and nominal GDP, the former being the Grainger causes for the latter, which mainly arises from the improvement in the institution of the stock market and the larger ratio of the stock market capitalization to that of nominal GDP. In addition, the increasing liquidity of long-term stock market and investors' speculation to the stock market based on the national macro-control policies also elucidated the inherent property of Shanghai Composite Index as a leading indicator of Chinese Nominal GDP in the results presented.
\end{abstract}

\section{Keywords}

Nominal GDP, Shanghai Securities Composite Index (SSCI), X-11 Process, Co-Integration Test, Primacy

\section{Introduction}

\subsection{Research Background}

Since the establishment of the securities trading center in 1991 and the gradual development of Chinese financial market, the gross value of the stock market has been accounted for a higher proportion in China's nominal GDP and the devel- 
opment of the stock market has been playing a more significant role in the augment of GDP. Especially in the milieu of the gradual opening-up of Chinese financial market, the interest rate liberalization and the internationalization of $\mathrm{RMB}$, the study on the relations between stock market and nominal GDP becomes more important. However, although nowadays the securities market in China has reached a certain scale after 20 years' development, there is still faultiness in the development of legal system, regulatory system, and market guidance system. Therefore, there must exist certain relationship between macroeconomic and securities markets in China.

The relationship between macroeconomic and securities markets has been a controversial mystery in economics circle. Neither the "classical consumption model" nor the "the puzzle of equity prices" can be resolved with a suitable theory. Nevertheless, a large number of financial researchers have achieved fruitful results in measuring and analyzing the impact of macroeconomic variables on the stock market from the asset pricing model.

Dejing Wang (2002) built up the co-integration model with monthly data of macroeconomic indicators and Shanghai Securities Composite Index, which showed that exchange rate, long-term interest rate and M2 had a negative impact on the stock market while short-term interest rate had a positive impact [1]. However, Xiao Zhao (2005), after analyzing the macroeconomic index and stock market through the co-integration model, draw a conclusion that only the growth rate of nominal GDP had an unstable positive correlation with stock index, and the other representative macroeconomic variables were irrelevant to the returns of the stock market [2]. Hong Taojie (2009) identified the correlation between the returns of Share A of SSCI and other six main macroeconomic variables from 1998 to 2007 with Bayesian Vector Auto-Regression Model, showing that the stock market returns have a positive correlation with industrial output growth, a negative correlation with CPI and long term interest rate, and an inconspicuous correlation with variables such as M2, exports and investment [3]. Quan Zhao (2012) made an empirical analysis of the data of Share A of Shanghai Securities Composite Index, the nominal GDP and M1, showing that every time a $1 \%$ rise in GDP would follow an increase in Shanghai Securities Composite Index by $2.55 \%$, vindicating that stock market had a positive correlation with the macro economy, and economic growth and monetary policy had a significant impact on stock market [4].

After a general survey of the fruitful researches of the correlation between micro-economic and stock market in China in recent years, the authors found that few scholars have studied the correlation and relativity between nominal GDP and the stock market index. Meanwhile, most scholars reach conclusions about the long-term co-integration relationship among the variables, while few draw attention to the study on lag correlation. Therefore, based on the co-integration model, and focused on the empirical analysis of Chinese nominal GDP and Shanghai Securities Composite Index, the present paper explores the causality of 
these two factors with the Granger causality test. Furthermore, the present research discusses the leading feature of the Shanghai Composite Index over nominal GDP by the Lagged regression model. Finally, reasons for these empirical results and policy recommendations are analyzed and advices put forward.

\subsection{Research Purpose}

The main purpose of the present research is to explore the correlation between the macroeconomic indicator and the stock market index, the reason for the correlation and the interaction mechanism between the two, and to probe into the relations of the financial development and economic development in China. Based on the correlation between the macroeconomic indicator and the stock market index, the paper possesses two main points of practical significance as the following. Firstly, this paper could offer new guidance for macroeconomic policy regulators to evaluate the effect of economic policies and provide empirical evidence for formulating securities market development plans and policies. Secondly, this paper could provide an empirical method for investors to analyze their investment, by which investors can not only predict the stock market index with the forecasted macroeconomic indicator, but also utilize the forecasted stock market index to predict the macroeconomic index.

\subsection{Research Method}

The present paper employs a X-11 process to eliminate the seasonal effect from the data of nominal GDP and Shanghai securities composite index from the first season of 1996 to that of 2015, conducts a Co-integration test and Granger causality test on these processed data, and analyzes the leading characteristic of the securities index with the Lagged regression model [5], Finally, a detailed analysis of the research results and some policy recommendations are provided.

This research mainly utilizes a measurement model to analyze the data. Based on the quarterly data of nominal GDP and SSE from 1996 to 2015, the present authors firstly apply X-11 process to eradicate the seasonal effect of the quarterly data to get the processed data. Subsequently, the sequence diagram and unit root test are implemented to determine the stability of the new data. After that, the ADF test is conducted on the first order differential data, and the EG two-step method is applied to explore whether there is long-term co-integration relationship in order to further discuss the volatility transmission relation between nominal GDP and Shanghai securities composite index. Lastly, the present research analyzes the co-integration relationship between the Lag period of Shanghai Securities Composite Index and nominal GDP with the lagged regression model, thus probing into the leading characteristic of SSE.

\section{Data}

\subsection{Choice of Variable}

The present paper selects seasonal data of nominal GDP from the first season of 
1996 to that of 2015 as the macroeconomic indicator, since only the nominal GDP can best reflect the level of China's macroeconomic development objectively. So the paper defined seasonal GDP as the dependent variable.

The present paper chooses monthly data of Shanghai Securities Composite Index from 1996 to that of 2015 as the stock market index (on a daily settlement basis). Considering the disparity in frequency and range of the volatility of monthly Shanghai Securities Composite Index data, we average the monthly Shanghai Securities Composite Index and get the seasonal Shanghai Securities Composite Index processed data. It serves as the independent variable.

\subsection{Data Processing}

\subsubsection{Sequence Diagram of Original Sequence}

From Figure 1, the quarterly Shanghai Securities Composite Index data shows an obvious uptrend and at every beginning of each year the index value will peak, with an obvious seasonal effect with a yearly cycle.

Figure 2 exhibits obviously that 1996-2015 quarterly nominal GDP also has an obvious seasonal effect with a pattern of yearly cycle as well as a pattern of uptrend. So even though we take logarithm on the data to deal with heteroscedasticity, the sequences will probably not bring convincing results in the co-integration test due to their seasonal effects.

\subsubsection{X-11 Process to Delete the Seasonal Effect}

Since the raw data sequences exhibit an apparent seasonal effect, the paper employs X-11 process to eliminate the seasonal effect of the original data sequences.

From Figure 3, X-11 process was a method original designed to adjust the seasonal effect of time series by USIB. The basic principle is the decomposition of deterministic factor of the time series. X-11 process is mainly used to eradicate the seasonal effect, trading day gap and random effect in order to get more accurate long-term trends [5].

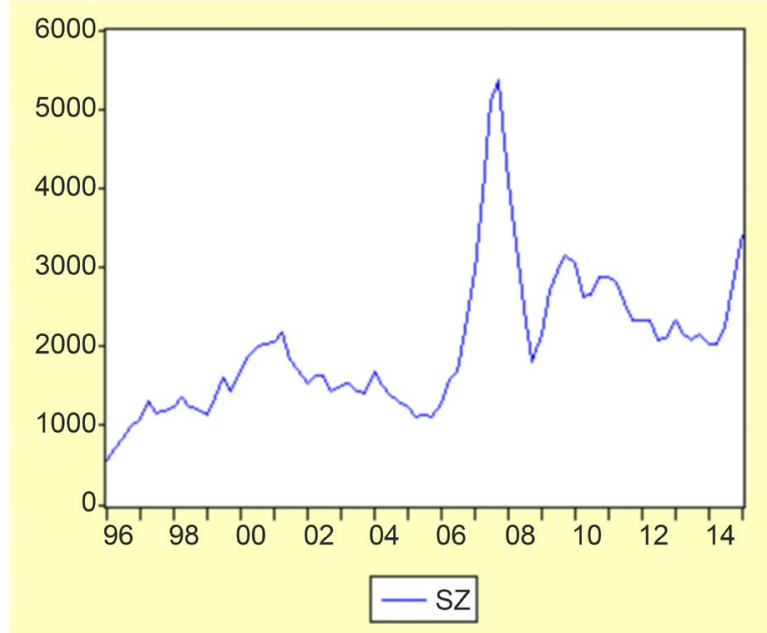

Figure 1. Sequence diagram of 1996-2015 quarterly Shanghai Composite Index. Data source: National Bureau of Statistics. 


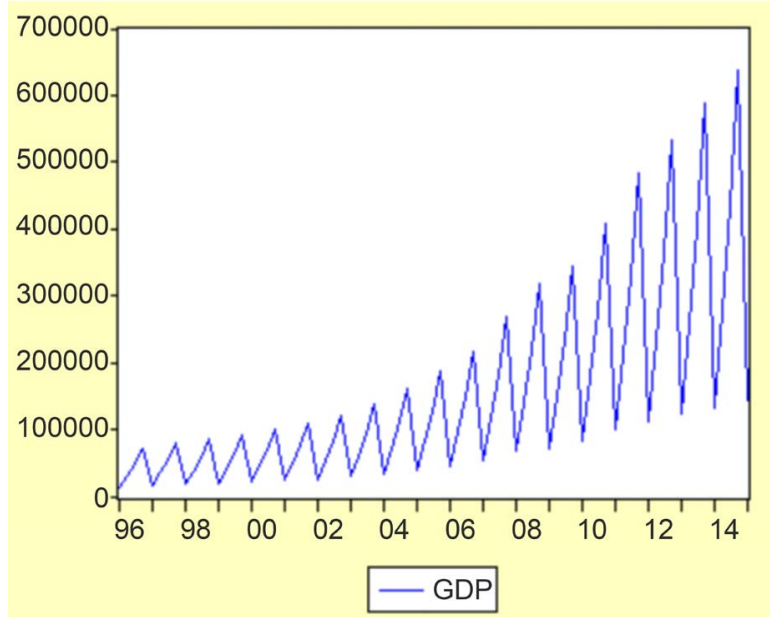

Figure 2. Sequence diagram of 1996-2015 quarterly nominal GDP. Data source: National Bureau of Statistics.

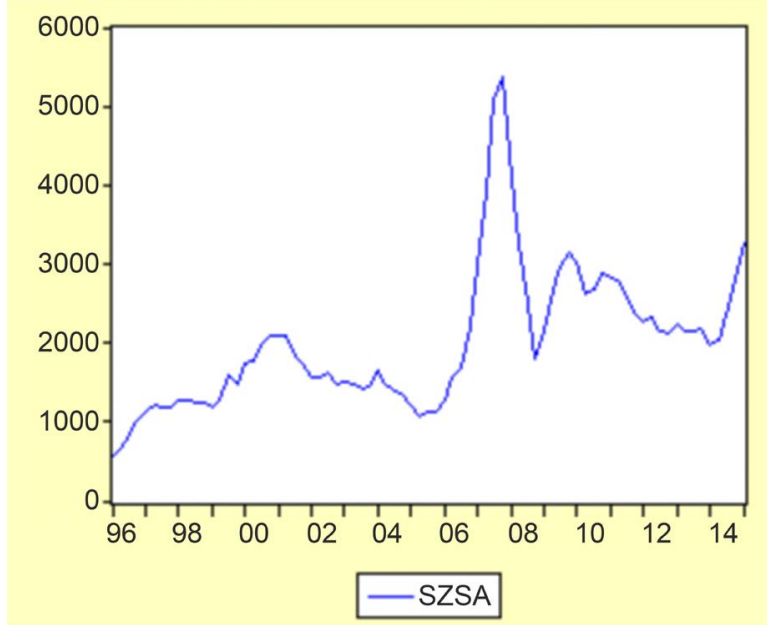

Figure 3. Sequence diagram of quarterly Shanghai Securities Composite Index after X-11 process. Data source: Wind.

According to Figure 4, after employing X-11 process, we can eliminate the seasonal effect of the quarterly nominal GDP and Shanghai Securities Composite Index, and then we can conduct co-integration test for the processed data.

\section{Empirical Analysis}

\subsection{Stationary Test}

Before conducting a Stationary Test, in order to reduce the heteroscedasticity of the data as much as possible, we took logarithm on the processed data after the $\mathrm{X}-11$ process, and obtained two data sequence $\ln ($ gdpsa) and $\ln (\mathrm{szsa})$.

\subsubsection{Sequence Diagram}

In the Sequence Diagram (Figure 5), $\ln$ (gdpsa) and $\ln$ (szsa) both exhibit an uptrend, the former a smooth continuously rise while the latter a serrated rise 


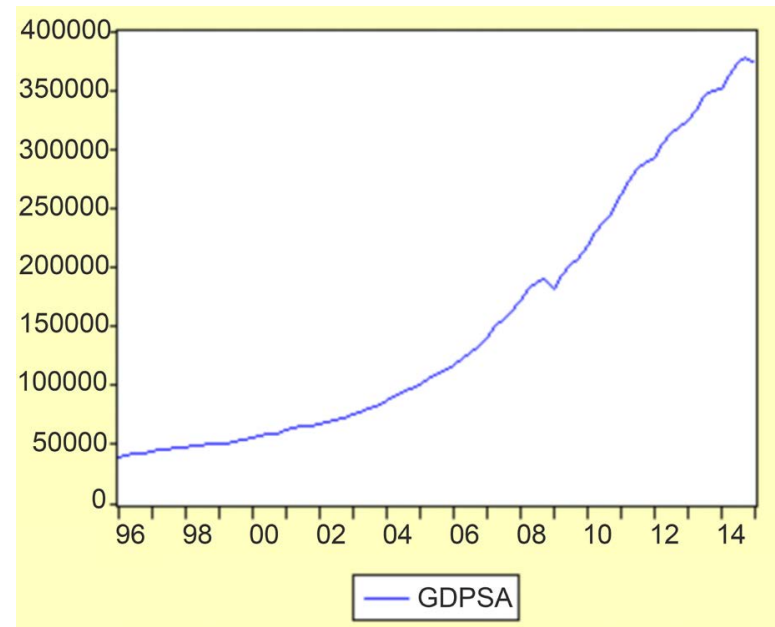

Figure 4. Sequence diagram of quarterly nominal GDP after $\mathrm{X}-11$ process. Data source: self processing.
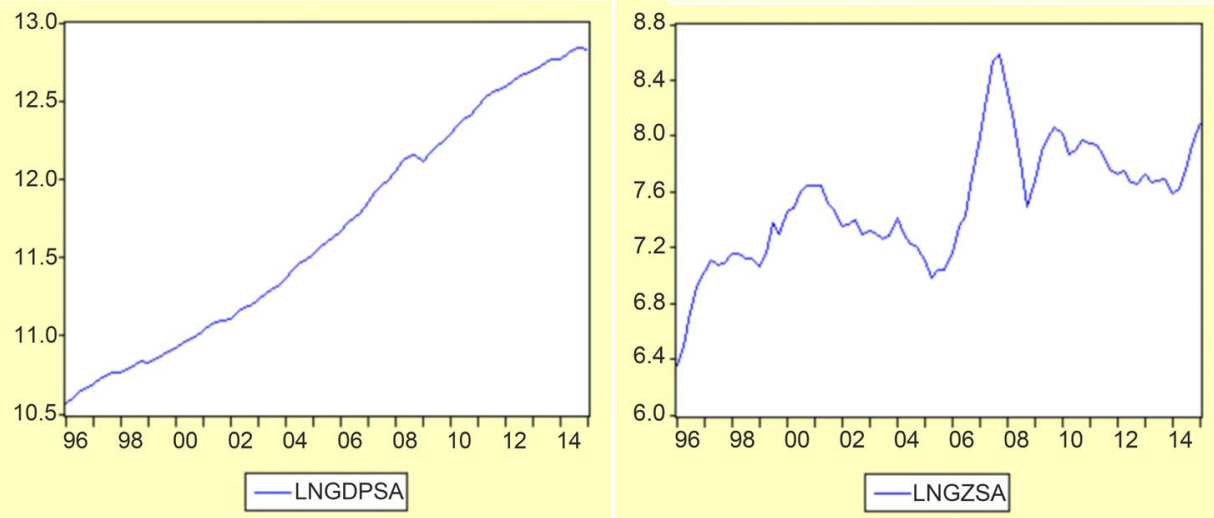

Figure 5. Sequence Diagram of $\ln ($ gdpsa) and $\ln ($ szsa). Data source: National Bureau of Statistics and Wind.

accompanied with fluctuations, so it can be deduced that the two sequences are non-stationary. Thus we needed to conduct ADF tests on the processed data.

\subsubsection{ADF Unit Root Test}

To obtain accurate estimation of stationary for the dealt data, we use ADF unit root test and the testing result is as Table 1 follows.

In Table $2, \ln$ (gdpsa) and $\ln$ (szsa) fail the test at the significant level of $5 \%$ and therefore the sequences are non-stationary. Accordingly, we applied the first order difference, obtaining the diagram of the first order differential sequences, marked in the following as $\ln$ (gdpsa) and $\ln$ (szsa) .

In Figure 6, $\ln$ (gdpsa) and $\ln$ (szsa) exhibit an obvious stationary characteristic, with the latter sequence showing a random walk pattern around 0. Accordingly we also conduct ADF unit root test on $\ln$ (gdpsa) and $\ln$ (szsa) .

Table 3 and Table 4 show that $\ln$ (gdpsa) and $\ln$ (szsa) can pass the test at the $1 \%$ significant level. Therefore, the first order differential sequences of $\ln$ (gdpsa) and $\ln$ (szsa) are stationary, satisfying the premise of the cointegration test. 
Table 1. ADF Testing Result of ln(gdpsa) (Type Three).

\begin{tabular}{ccccc}
\hline \multirow{2}{*}{ ADF test statistic } & P value & \multicolumn{3}{c}{ Test critical values } \\
\cline { 3 - 5 } & & 1\% level & 5\% level & $10 \%$ level \\
\hline-1.726196 & 0.7299 & -4.08509 & -3.47085 & -3.162458 \\
\hline
\end{tabular}

Data source: self processing.

Table 2. ADF Testing Result of $\ln ($ szsa) (Type Three).

\begin{tabular}{ccrcc}
\hline \multirow{2}{*}{ ADF test statistic } & P value & \multicolumn{3}{c}{ Test critical values } \\
\cline { 3 - 5 } & & $1 \%$ level & $5 \%$ level & $10 \%$ level \\
\hline-2.782018 & 0.0657 & -3.520307 & -2.900670 & -2.587691 \\
\hline
\end{tabular}

Note: type one means none; type two means intercept; type three means intercept and trend (The same as follows). Data source: self processing.

Table 3. ADF Testing Result of the First Order Difference of ln(gdpsa) (type two).

\begin{tabular}{ccccc}
\hline \multirow{2}{*}{ ADF test statistic } & P value & \multicolumn{3}{c}{ Test critical values } \\
\cline { 3 - 5 } & & $1 \%$ level & $5 \%$ level & $10 \%$ level \\
\hline-5.843974 & 0.0000 & -3.520307 & -2.900670 & -2.587691 \\
\hline
\end{tabular}

Data source: self processing.

Table 4. ADF Testing Result of the First Order Difference of $\ln$ (szsa) (type one).

\begin{tabular}{ccccc}
\hline \multirow{2}{*}{ ADF test statistic } & P value & \multicolumn{3}{c}{ Test critical values } \\
\cline { 3 - 5 } & & $1 \%$ level & $5 \%$ level & $10 \%$ level \\
\hline-4.649604 & 0.0000 & -2.596160 & -1.945199 & -1.613948 \\
\hline
\end{tabular}

Data source: self processing.
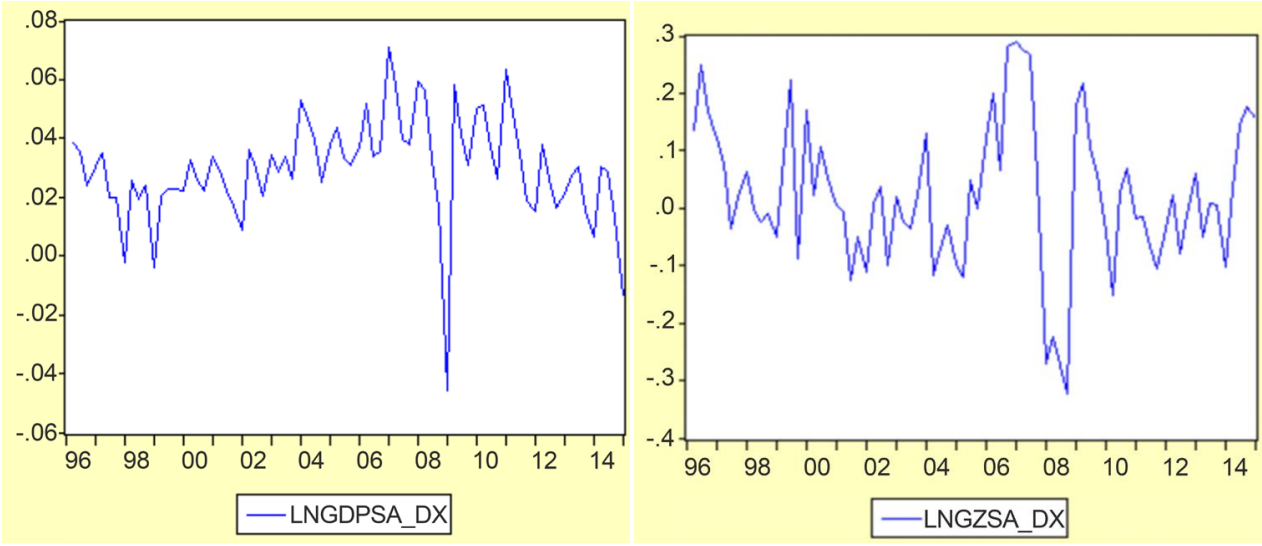

Figure 6. Sequence Diagram of $\ln ($ gdpsa) and $\ln ($ szsa). Data source: self processing.

\subsection{Cointegration Test}

The stationary test shows that $\ln$ (gdpsa) and $\ln$ (szsa) are first-order singlesequences, conform to the requirement of the cointegration test, so we examine the cointegration between $\ln$ (gdpsa) and $\ln$ (szsa) by means of the EG two-step 
method.

\subsubsection{Construction of Regression Model}

By constructing the regression model of $\ln$ (gdpsa) and $\ln$ (szsa) with OLS, we obtain two fitting forms of the model, the former including constant term while the latter not. The fitting results are as follows.

$$
\begin{gathered}
\ln (\text { gdpsa })=2.635+1.202 * \ln (\text { szsa }) \\
(2.44) \quad(8.41) \\
R^{2}: 0.48, D W: 0.08, F: 70.68 \\
\ln (\text { gdpsa })=1.5519 * \ln (\text { szsa })
\end{gathered}
$$

$$
R^{2}: 0.48, D W: 0.08, F: 187.52 ;
$$

According to the fitting result, regression model one and regression model two can both pass the model test and the parametric test with a coefficient of determination close to 0.5 , reflecting the existence of a certain linear relationship between the two variables. Therefore they are both effective models. However, according to the principle of minimum information quantity, we obtain the following results of model optimization:

From Table 5, AIC and SBC in regression model one are smaller than that in regression model two, but the coefficient of determination in model one is larger, suggesting model one with better goodness of fit and less amount of information. Based on above results, we choose model one as our sample fitting model.

\subsubsection{Residual Test and Construction of Dynamic Regression Model}

By observing the sequence diagram of residual sequence in model one, we deduce preliminarily that the residual sequence in model one fluctuates around 0 randomly, suggesting a stationary sequence from Figure 7. Thus we conduct $\mathrm{ADF}$ unit root test on the residual sequence, and the results are as follows in $\mathrm{Ta}$ ble 6.

According to the result of first order lag in type one testing, we have $97.92 \%$ confidence to consider the residual sequence is stationary with first order autocorrelation.

$$
\varepsilon_{t}=0.9600006874 * \varepsilon_{t-1}+v_{t}, v_{t} \stackrel{i, i, d}{\sim} N\left(0, \sigma^{2}\right) ;
$$

The above equation suggests that we have $97.92 \%$ confidence to consider that there is cointegratioen relationship between $\ln$ (gdpsa) and $\ln$ (szsa), and hence we construct a dynamic regression model as follows:

$$
\ln (\text { gdpsa })=\alpha+\beta * \ln (\text { szsa })+\frac{v_{t}}{1-\phi_{1} B}, v_{t}^{i, i, d} \sim N\left(0, \sigma_{v}^{2}\right) ;
$$

Then the caliber of the dynamic regression model is obtained by using the conditional least square estimation method, as follows: 
Table 5. Model Optimization Results Fitting model AIC SBC coefficient of determination.

\begin{tabular}{cccc}
\hline Fitting model & AIC & SBC & coefficient of determination \\
\hline $\ln ($ gdpsa $)=2.635+1.202 * \ln ($ szsa $)$ & 1.59 & 1.65 & 0.48 \\
$\ln ($ gdpsa $)=1.5519 * \ln ($ szsa $)$ & 1.64 & 1.67 & 0.44 \\
\hline
\end{tabular}

Data source: self processing.

Table 6. ADF Testing result of residual sequence in model one (type one).

\begin{tabular}{ccccc}
\hline \multirow{2}{*}{ ADF test statistic } & P value & \multicolumn{3}{c}{ Test critical values } \\
\cline { 3 - 5 } & & $1 \%$ level & $5 \%$ level & $10 \%$ level \\
\hline-2.315432 & 0.0208 & -2.59160 & -1.945199 & -1.613948 \\
\hline
\end{tabular}

Data source: self processing.

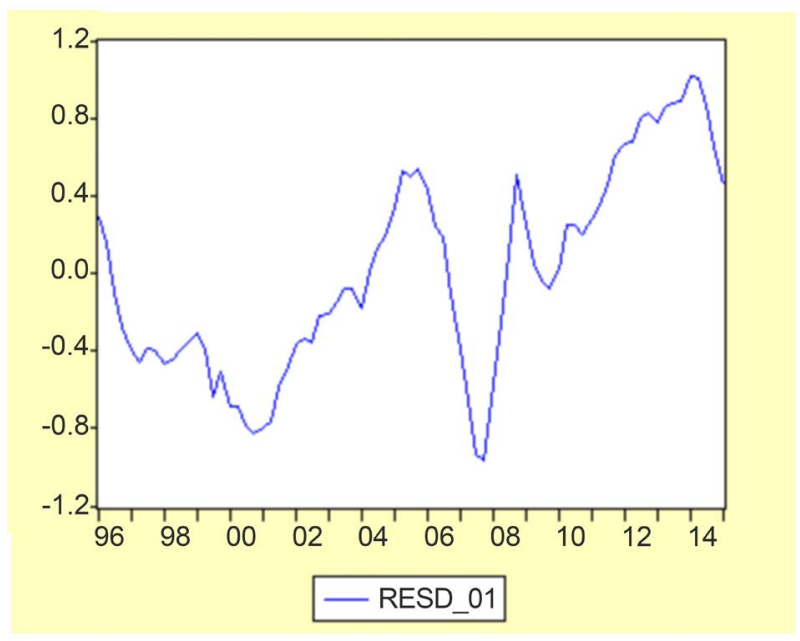

Figure 7. Sequence diagram of residual sequence in model one. Data source: self processing.

$$
\ln (\text { gdpsa })=2.6351+1.2024 * \ln (\text { szsa })+\frac{v_{t}}{1-0.9600 B}, v_{t} \stackrel{i, i, d}{\sim} N(0,0.023)
$$

According to the dynamic regression model, we draw a fitting chart as Figure 8 follows:

The fitting chart above shows that the fitting effect of dynamic regression model is generally satisfying, because the general fitting trend and nominal GDP tend to be in accordance, indicating the stationary long-term cointegration relationship. But the forecast line (in red) has an overall fluctuation, and deviate from the nominal GDP especially during the financial crisis in 2008 which results in the most extreme discrepancy between the two lines.

\subsection{Granger Causality Test}

After cointegration test, we have found that there is a long-term equilibrium between $\ln$ (gdpsa) and $\ln$ (szsa) (the nominal GDP and Shanghai securities 


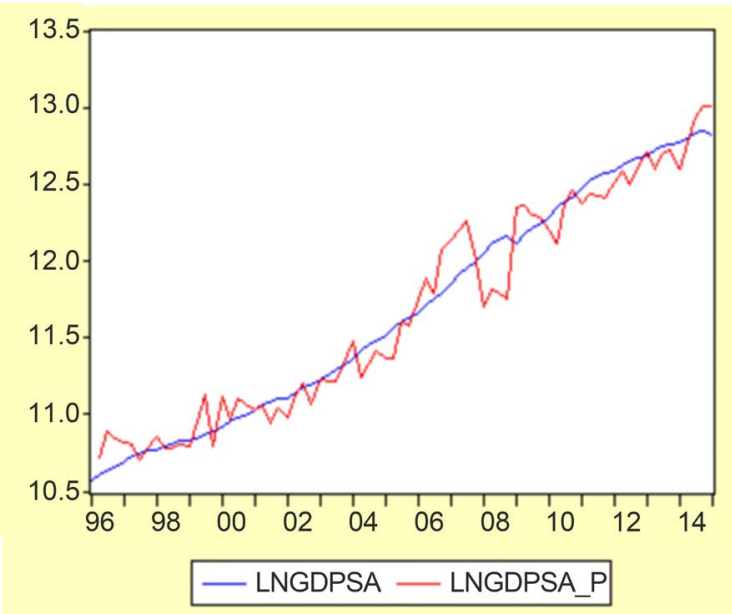

Figure 8. The fitting chart of dynamic regression model. Data source: self processing.

composite index after X-11 process). In order to explore causality between the two variables, Granger causality test is performed to examine the causality and the testing result is as follows:

Table 7 indicates that the concomitant probability of the first test is 0.026 , showing that at confidence level below $95 \%$, it can be concluded that $\ln$ (szsa) dose granger cause $\ln$ (gdpsa), but not conversely, further indicating that nominal GDP can be interpreted by Shanghai securities composite index to a great degree.

\subsection{Test on the Primacy of Shanghai Securities Composite Index}

\subsubsection{Construction of Lagged Regression Model}

Considering that Shanghai Securities Composite Index may lead nominal GDP, we adjust the regression model above with lagged data of $\ln$ (szsa), forming different fitting types of lagged regression model.

$$
\ln (\text { gdpsa })_{t}=\alpha+\beta * \ln (\mathrm{szsa})_{t-n}, n=0,1,2,3,4 \ldots
$$

The study utilizes OLS to fit the lagged regression model above for multiple lag period, and obtains different fitting forms of lagged regression models.

From Table 8, along with the increased lag orders, the coefficient of determination firstly decreases and then increases, reaching maximum at the 14th order lag, and after 14th order lag the coefficient of determination drops significantly. But the value of AIC and SBC that represent the amount of information is decreasing all the way. Inferring from the maximum coefficient of determination and the minimum information criterion, we consider the regression model of 14th order lag is relatively optimal and the regression model at this point achieves the Optimal fitting degree.

\subsubsection{Co-Integration Test and Construction of Dynamic Regression Model}

From Figure 9, we deduce that the residual sequence in regression model of 
Table 7. The result of Granger causality test (lag 3 order).

\begin{tabular}{cccc}
\hline Null Hypothesis: & Obs & F-Statistic & Probability \\
\hline LNSZSA does not Granger Cause LNGDPSA & 74 & 3.2986 & 0.02559 \\
LNGDPSA does not Granger Cause LNSZSA & & 2.65942 & 0.05521 \\
\hline
\end{tabular}

Data source: self processing.

Table 8. Regression result fitted by different lag orders of $\ln ($ szsa).

\begin{tabular}{|c|c|c|c|}
\hline Fitting types of lagged regression model & AIC & SBC & $\begin{array}{l}\text { Coefficient of } \\
\text { determination }\end{array}$ \\
\hline LNGDPSA $=2.635141425+1.2023834 \times$ LNSZSA & 1.5921 & 1.6530 & 0.4852 \\
\hline LNGDPSA $=2.745755679+1.190818606 \times \operatorname{LNSZSA}(-1)$ & 1.5873 & 1.6487 & 0.4787 \\
\hline LNGDPSA $=2.8809214+1.175643995 \times \operatorname{LNSZSA}(-2)$ & 1.5789 & 1.6407 & 0.4744 \\
\hline LNGDPSA $=3.00108961+1.162086225 \times \operatorname{LNSZSA}(-3)$ & 1.5608 & 1.6231 & 0.4754 \\
\hline LNGDPSA $=3.086412264+1.152881812 \times \operatorname{LNSZSA}(-4)$ & 1.5317 & 1.5944 & 0.4820 \\
\hline LNGDPSA $=3.174676559+1.143214922 \times \operatorname{LNSZSA}(-5)$ & 1.5028 & 1.5660 & 0.4885 \\
\hline LNGDPSA $=3.299789339+1.128841383 \times \operatorname{LNSZSA}(-6)$ & 1.4846 & 1.5484 & 0.4897 \\
\hline LNGDPSA $=3.411684718+1.116236439 \times \operatorname{LNSZSA}(-7)$ & 1.4626 & 1.5268 & 0.4927 \\
\hline LNGDPSA $=3.512422914+1.10512384 \times \operatorname{LNSZSA}(-8)$ & 1.4368 & 1.5016 & 0.4973 \\
\hline LNGDPSA $=3.632856908+1.091550853 \times$ LNSZSA $(-9)$ & 1.4132 & 1.4785 & 0.4998 \\
\hline LNGDPSA $=3.714518616+1.083038309 \times \operatorname{LNSZSA}(-10)$ & 1.3777 & 1.4435 & 0.5081 \\
\hline LNGDPSA $=3.790174249+1.075381919 \times \operatorname{LNSZSA}(-11)$ & 1.3387 & 1.4051 & 0.5176 \\
\hline LNGDPSA $=3.871270046+1.067191687 \times \operatorname{LNSZSA}(-12)$ & 1.3025 & 1.3694 & 0.5255 \\
\hline LNGDPSA $=3.964220943+1.057445709 \times \operatorname{LNSZSA}(-13)$ & 1.2625 & 1.3299 & 0.5337 \\
\hline LNGDPSA $=4.081095034+1.044604175 \times \operatorname{LNSZSA}(-14)$ & 1.2286 & 1.2966 & 0.5386 \\
\hline LNGDPSA = $4.22645113+1.028202701 \times \operatorname{LNSZSA}(-15)$ & 1.2080 & 1.2766 & 0.5369 \\
\hline LNGDPSA $=4.397603243+1.008513424 \times \operatorname{LNSZSA}(-16)$ & 1.1993 & 1.2685 & 0.5292 \\
\hline LNGDPSA $=5.238108788+0.908705425 \times \operatorname{LNSZSA}(-20)$ & 1.1982 & 1.2699 & 0.4757 \\
\hline LNGDPSA $=6.709738168+0.746863336 \times \operatorname{LNSZSA}(-30)$ & 1.0744 & 1.1532 & 0.3275 \\
\hline
\end{tabular}

Data source: self processing.

14th order lag resembles the latter part of the residual sequence in Figure 7 above which suggests the sequence is stationary. Then we also perform ADF unit root test on the residual sequence in 14th order lag regression model, and the result is as follows in Table 9.

According to the result of first order lag in type one testing, we have $96.01 \%$ confidence to consider that the residual sequence is stationary with first order autocorrelation.

$$
e_{t}=0.9583613477 * e_{t-1}+v_{t}, v_{t}^{i, i, d} \sim N\left(0, \sigma^{2}\right) ;
$$

It means that we have $96.01 \%$ confidence to consider that there is a long-term edcointegration relationship between $\ln (\text { gdpsa })_{t-14}$ and $\ln (\mathrm{szsa})_{t}$ and we construct a dynamic regression model as follows: 


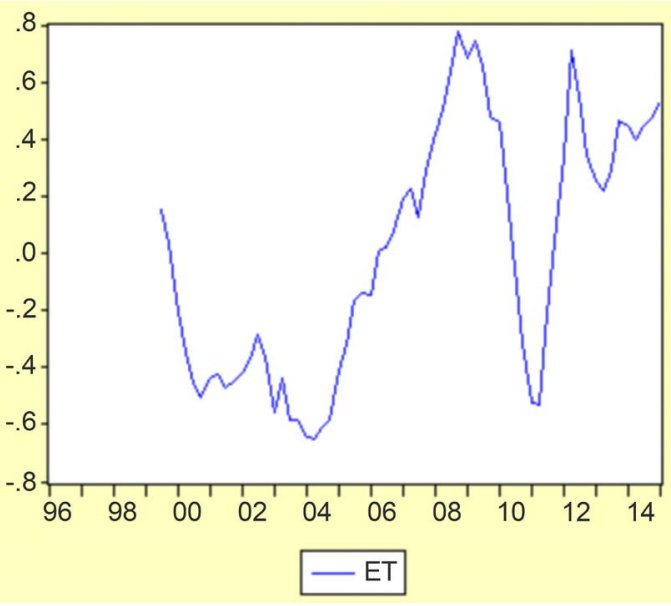

Figure 9. Sequence diagram of residual sequence in lagged 14 orders regression model. Data source: self processing.

Table 9. ADF testing result of residual sequence in lagged 14 orders regression model.

\begin{tabular}{ccccc}
\hline \multirow{2}{*}{ ADF test statistic } & \multirow{2}{*}{ P value } & \multicolumn{3}{c}{ Test critical values } \\
\cline { 3 - 5 } & & $1 \%$ level & $5 \%$ level & $10 \%$ level \\
\hline-2.047009 & 0.0399 & -2.603423 & -1.946253 & -1.613345 \\
\hline
\end{tabular}

Data source: self processing.

$$
\ln (\text { gdpsa })_{t}=\alpha+\beta * \ln (\text { szsa })_{t-14}+\frac{v_{t}}{1-\phi_{1} B}, v_{t} \stackrel{i, i, d}{\sim} N\left(0, \sigma_{v}^{2}\right)
$$

Then the caliber of the dynamic regression model is obtained by using the Conditional least squares estimation method, as follows:

$$
\ln (\text { gdpsa })_{t}=4.0811+1.0446 * \ln (\text { szsa })_{t-14}+\frac{v_{t}}{1-0.9584 B}, v_{t}^{i, i, d} \sim(0,0.19)
$$

According to dynamic regression model, we draw a fitting chart as follows:

Figure 10 shows that the fitting effect of dynamic regression model of 14 th order lag is better than that in the fitting chart in previous section, indicating that the linear correlation between 14th order lag of Shanghai Composite Index and nominal GDP is the highest, and we have $96.01 \%$ confidence to consider that there exists a long-term cointegration relationship between them, and such high degree of linear correlation will tend to last stably.

Hence, the research concludes that Shanghai Securities Composite Index has a leading feature over nominal GDP, spanning 3.5 years in China.

\section{Cause Analysis of Empirical Results}

The empirical analysis in the previous section shows that firstly there is a long-term co-integration relationship between two variables and the Shanghai Composite Index is the Granger cause for nominal GDP. Secondly the Shanghai Composite Index precedes nominal GDP roughly 3.5 years ahead. What follows in the paper is a cause analysis of the empirical results. 


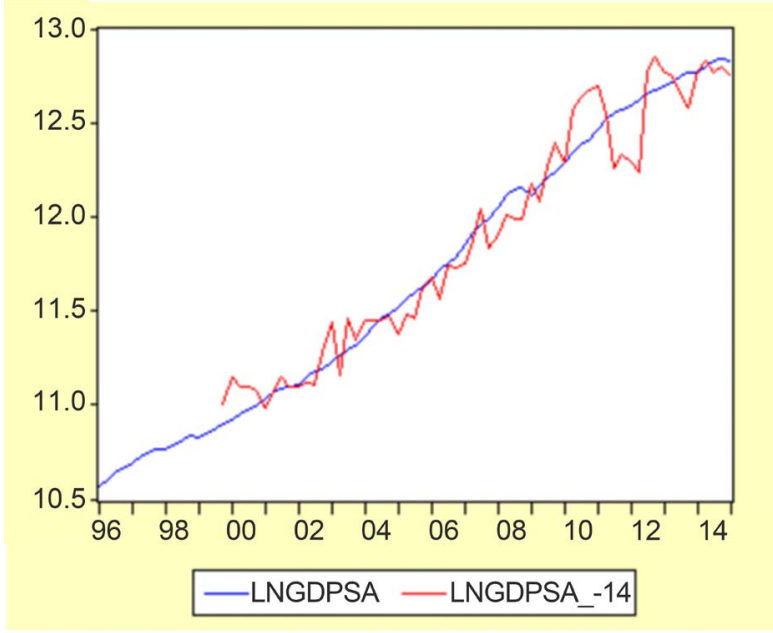

Figure 10. The fitting chart of dynamic regression model of 14 lag orders. Data source: self processing.

\subsection{The Analysis of the Causes of the Long-Term Co-Integration Relationship}

The dynamic regression equation shows that in the long term, if Shanghai Securities Composite Index rises 1\%, the nominal GDP will follow by a $1.2 \%$ rise, suggesting that the rise in stock index would lead to greater growth in macro economy, and meaning that the Shanghai Securities Composite Index has an augmented effect on nominal GDP. Therefore, the stock market can serve as an economic booster of macro economy and its steady and rapid development plays an important role in the development of China's macro economy. The Shanghai Securities Composite Index has a long-term positive co-integration relationship with nominal GDP, and has an augmented effect on nominal GDP. This study attempts to analyze the causes from the following several evidence-based results.

First, this paper argues that with the gradual development of financial market, China's stock market becomes more effective by successive steps, serving as the main reason for the long-term positive co-integration relationship between the Shanghai Securities Composite Index and nominal GDP. The increasing perfection of the stock market has gradually enhanced its market effectiveness, which will have a counterforce on macro economy to stimulate its growth, such as promoting the optimal allocation of funds in the real economy, increasing the rate of utilization of capital so that capital will be directed to more truly valuable enterprises, and spurring the growth of the real economy. Therefore, the stock market under the improving stock market system, is becoming gradually effective, contributing to the positive long-term dynamic equilibrium between Shanghai composite index and nominal GDP.

Second, the steadily increasing proportion of the scale of stock market funds in nominal GDP shows that the stock market has gradually become a main investment market of the domestic currency market, namely, the stock market has also gradually become a main venue for domestic currency. The results of the 
proportion of circulation A-shares market value in nominal GDP are shown in Figure below.

In the above graph, the proportion of circulation A-share market value in nominal GDP has a strong upward trend after 2005, and the proportion stays constant at 35\% in 2011 and later. From the perspective of the capital size proportion, the correlation between nominal GDP and the Shanghai Securities Composite Index is becoming stronger, and the enhanced stability of the proportion indicates the correlation tends to be stable, further accounting for the empirical results that there is a long-term co-integration relationship between Shanghai composite index and nominal GDP.

\subsection{Cause Analysis of Precedence of the Shanghai Securities Composite Index over Nominal GDP}

Classical finance theories state that the price of the stock is the discounted value of the company's future earnings, and the future earnings of a company and macro economy are highly correlated, meaning investors make stock investment decisions based on expectation. The precedence of Shanghai Securities Composite Index over nominal GDP conveys the primacy that investors have promising expectations of the future of Chinese macro economy. Such primacy is determined by the degree of participation in stock market of investors.

First of all, from 1996 to early 2015, China's nominal GDP continues a rising trend, and the upward trend shows strong momentum since optimistic expectations of investors about Chinese macro economy are in accordance, in the long run causing more speculators to exit from the bond market and head for the stock market, and attenuating the overall participation in the bond market. Compared to the liquidity of the bond market, the liquidity of stock market is relatively increased. Therefore, in a long term perspective, stock market liquidity has a stronger leading role than macro economy, thereby the appreciated Shanghai Securities Composite Index has certain precedence over macro economy.

Simultaneously, macro-control policies introduced regularly by Chinese government will also invoke investors' reaction on the stock market in advance of the modification of the macroeconomic data, leading to a result of precedence of Shanghai Securities Composite Index over macro economy. In recent years there have been numerous situations when investors overreact due to their expectation based on the government macro-control. At the end of June 2013, tension of the liquidity in current market led to the pervasive expectation of investors that the central bank would adopt an act of financial rescue. As a result, the stock market fluctuated fiercely, the trading volume amplified and the stock market liquidity was intensified. At last the Macro economic data consequently showed improvement in the third quarter, elucidating that stock market index precedes macro economy. Since November 2014, the two interest rate cuts and two RRR (reserve requirement ratio) cuts all have ensured investors bullish expectation on the stock market and caused the fluctuating of the stock market. The Shanghai Securities Composite Index once reached 4500 points, while the 
growth of macroeconomic indicators show relatively weakness-a prove that Shanghai Securities Composite Index precedes.

The increased liquidity and the expectation of investors based on monetary policies will directly affect the stock market first and contribute to the above mentioned precedence.

\section{Conclusions}

The present paper implements X-11 process to eliminate the seasonal effect from the data of nominal GDP and Shanghai Securities Composite Index from the first season of 1996 to that of 2015, conducts a Co-integration test and Granger causality test on these processed data, and analyzes the precedence of the securities index with the Lagged regression model. Finally, after a detailed analysis of the research results, the following conclusions are made:

1) The nominal GDP and SSE have a long-term co-integration relationship, and the SSE is a Granger cause for nominal GDP.

2) The improvement of stock market system and the steadily increasing proportion of the stock market circulation value in nominal GDP mainly contribute to the long-term co-integration relationship.

3) SSE has precedence over nominal GDP, and the leading time is about 3.5 years.

4) The improvement of long-term stock market circulation and the pre-motion of the investors based on the government's macro-control policy can shed light on the evidence-based precedence.

At the end, there are three suggestions that are provided by our research. Firstly, National Monetary Authority must make good utilization of macro currency regulation tools to stabilize the proportion of the stock market circulation value in nominal GDP, so that the stock market could promote macro economy growth. Secondly, with the increasingly significant role of China's financial market in development of macro economy, the State Council should establish more favorable market systems conducive to the effectiveness of the financial market to consummate the stock market, and to maintain the long-term co-integration relationship between nominal GDP and Shanghai Securities Composite Index [6]-[12]. Thirdly, Legislature should reinforce the governing of the listed company, quicken trial implementation, consummate listing registration system and stock delisting provision, and promote a steady and healthy development of the stock market [13].

\section{Conflicts of Interest}

The author declares no conflicts of interest regarding the publication of this paper.

\section{References}

[1] Wang, D.-J. (2002) A Study on the Relationship between Xacroeconomic Variables and the Stock Market of China. Southwestern University of Finance and Economics, 
Chengdu.

[2] Zhao, X. (2005) Cointegration Analysis of the Impact of Macroeconomic on Stock Market Returns. Capital University of Economics and Business, Beijing.

[3] Jie, H.-T. and Zhou, S.-F. (2009) A Study on the Dynamic Relationship between Macro Economy and Stock Market in China: 1998-2007. Statistics \& Decision, 3, 112-113.

[4] Zhao, Q. (2012) The Research on the Relationship between Macro Economy and Stock Market in Post Crisis Era. China Economic \& Trade Herald, 29, 20-21.

[5] Guo, Q. and Xiang, J.-T. (1993) X-11 Seasonal Adjustment Method for Economic Time Series (I). Journal of Applied of Statistics and Management, 1, 52-63.

[6] Österholm, P. (2016) The Long-Run Relationship between Stock Prices and GDP in Sweden. Economic Notes, 45, 283-297. https://doi.org/10.1111/ecno.12057

[7] Gonzalo, J., Lee, T.-H. and Yang, W.P. (2008) Permanent and Transitory Components of GDP and Stock Prices: Further Analysis. Macroeconomics and Finance in Emerging Market Economies, 1, 105-120.

[8] Li, N., Ayling, D.E. and Hodgkinson, L. (2003) An Examination of the Information Role of the Yield Spread and Stock Returns for Predicting Future GDP. Applied Financial Economics, 13, 593-597. https://doi.org/10.1080/0960310022000040706

[9] Feinberg, M. and Tokic, D. (2003) ITC Investment, GDP and Stock Market Values in Asia-Pacific NIC and Developing Countries. Journal of the Asia Pacific Econo$m y$, 9, 70-84.

[10] Zietz, J. and Zhao, X.L. (2009) The Response of Household Incomes to Stock Price and GDP Growth by Income Quantile. Applied Economics, 41, 1501-1512. https://doi.org/10.1080/00036840601032151

[11] Kaitila, V. (2016) GDP Growth in Russia: Different Capital Stock Series and the Terms of Trade. Post-Communist Economies, 28, 129-145. https://doi.org/10.1080/14631377.2015.1124556

[12] Franses, P.H. and Meesm, H. (2011) Does News on Real Chinese GDP Growth Impact Stock Markets? Applied Financial Economics, 21, 61-66.

[13] Chen, X.-R. and Li, X.-Q. (2014) Empirical Research on the Correlation between Stock Market Volatility and Macroeconomic Fluctuations in China. Times Finance, 3, 250-251. 